УДК 811.111'367.3:161.2

DOI: $10.24144 / 2617-3921.2020 .18 .132-143$

Тетяна Почепецька

старший викладач кафедри англійської філології ДВНЗ «Ужсгородський національний університет» orcid.org/0000-0003-0156-8792

м. Ужсгород, Украӥна, +380505410541 tetiana.pochepetska@uzhnu.edu.ua

\title{
Незаконченное высказывание: к проблеме определения лингвистического статуса
}

Анотація. Стаття присвячена аналізу проблем щзо виникають при визначенні лінгвістичного статусу незакінченого висловлювання. Особливої актуальності иј дослідження набули з перенесенням акценту у вивченні мови з їі структурної організаиії на ї̈ функціонування. В статті розглядаються принципи організації синтаксичних структур. Дається визначення реченню. Виділяються його основні структурні категорії - предикативність та модальність. Аналізується його семантична структура. Визначаються основні складові, а саме, пропозиція та модус. У дослідженні також запропоновано перелік положень за якими розрізняються речення та висловлювання. Висвітлено теоретичні засади та конщепції дослідження висловлювання. Окрему увагу приділено апарату реалізації комунікативних функиій мови, щзо зумовлюе доцільність ї̈ моделей $i$ можливість комунікативно - інтенційного варіювання у мовному спілкуванні. В публікації пропонується функиіональна модель для інтерпретації $i$ вивчення незакінчених висловлювань. Наголошується на необхідність їх інтерпретаиії не з точки зору неповноти, а з боку їх власних специфічних структурних властивостей та функцій. В статті також акцентується вагомість фактора адресата при розгляді незакінчених висловлювань.

Ключові слова: лінгвістичний статус, синтаксична структура, незакінчене висловлювання, речення, предикативність, модальність, семантична структура, пропозиція, модус, комунікативно - інтенційне варіювання, фактор адресата.

Abstract. The article deals with the analysis of problems that arise when defining the linguistic status of stop-short utterances. These studies have become especially relevant with the shift of emphasis in the study of the language from its structure to its functioning. The article considers the principles of organization of syntactic structures. The definition of the sentence is being given. Its main structural categories are distinguished - predicativity and modality. Its semantic structure is being analyzed. The main components are determined, namely, the proposition and 
the mode. The study also offers a list of provisions that distinguish between sentences and utterances. Theoretical principles and concepts of the research of the utterance are highlighted. Particular attention is paid to the devices of realization of communicative functions of the language, which determine the expediency of its models and the possibility of communicative - intentional variation in the language communication. The publication proposes a functional model for the interpretation and study of stop-short utterances. It is emphasized that they should be interpreted not in terms of incompleteness, but in terms of their own specific structural properties and functions. The article also stresses the importance of taking into consideration the addressee factor when considering stop-short utterances.

Keywords: linguistic status, syntactic structure. stop-short utterance, sentence, predicativity, modality, semantic structure, proposition, mode, communicative - intentional variation, the addressee factor.

Введение. Многообразие форм и значительное варьирование степени неполноты незаконченного высказывания от "But...", “So...", "But here...” до "I'm your second...", “You all know what I think...”, выдвигает на первый план необходимость определения их лингвистического статуса, В частности, естественным и закономерным здесь является вопрос, возможно ли отнести незаконченные высказывания типа “But...”, “So...” и т.д. к незаконченным реализациям структурно-семантической модели предложения.

Многочисленные попытки определения предложения и его существенных признаков делались на протяжении всей истории развития лингвистики. Современный этап развития теории предложения позволяет выделить два аспекта в его описании: синтаксический и семантикосинтаксический.

В предложении как особой синтаксической конструкции, имеющей в основе своего построения грамматический образец и специально предназначенной для того, чтобы быть сообщением, выделяются два основных содержательных признака, формирующих и характеризующих его как целостную структуру: предикативность и модальность.

Следует отметить, что если модальность определяется в лингвистике более или менее однозначно, как категория «обозначающая отношение действия к действительности, устанавливаемое говорящим лицом» [5, с. 3] конкретнее - выражающая отношение содержания предложения к действительности в плане реальности и ирреальности, то предикативность трактуется по-разному.

Как категория, которая по своему содержанию уже, чем модальность, так как последняя может выявляться как в области грамматических элементов языка, так и в области его лексико-номинативных элементов. Сторонники этой точки зрения определяют предикативность как синтаксическую модальность «особое языковое свойство предложения, реализующее его качественную 
определенность именно как предложения и, следовательно, не присущее ни одной другой единице языка» [3, с. 98].

Как понятие более широкое, чем модальность, заключающееся в отнесении содержания предложения к действительности, выраженное в категориях модальности, времени и лица [5, с. 16]. Центром предикации в предложении глагольного строя является глагол в личной форме. Кроме глагола предикация может быть выражена интонацией, порядком слов и различными служебными словами.

Часто предикативность рассматривается не как основной содержательный признак всего предложения, а лишь его конструктивного минимума, структурной схемы, которая реализуется, или развертывается с помощью синтаксических приемов распространения в полную структурную модель [10, с. 541-542; 15, с. 113].

Выделяются две основных единицы конструктивного минимума предложения: подлежащее и сказуемое, которые могут быть распространены при помощи определителей до группы подлежащего и группы сказуемого. В зависимости от того обе группы представлены в предложении или только одна им них предложения делятся на двусоставные и односоставные.

Итак, таковы основные содержательные характеристики предложения, к ним можно добавить следующие формально-грамматические признаки:

1. целостность, т.е. неделимость далее на речевые единицы с теми же основными структурными признаками;

2. автономность, т.е. отсутствие грамматических показателей включения в большую грамматическую форму;

3. грамматическая замкнутость, т.е. наличие только внутренних грамматических связей;

4. законченность - интонационная и грамматическая [5, с. 3 ; 19, с. 8]. Методы. В статье используются общенаучные методы исследования. Такие как: обобщение - мысленное выделение, фиксирование каких нибудь общих существенных свойств, принадлежащих только данному классу предметов или отношений; абстрагирование как теоретическое обобщение позволяющее отразить основные закономерности объектов или явлений, формализация как отображение содержательного знания в знаково-символическом виде, анализ и синтез как выделение в объекте основного и существенного, незаметного эмпирическому зрению.

Мы также используем взаимосвязь таких понятий как обобщуение (переход от единичного к общему, от менее общего к более общему) $u$ конкретизация (обратный переход - от более общего к менее общему, от общего к единичному). Если обобщение используется нами при формировании понятий, то конкретизация используется при описании конкретных ситуаций с помощью сформированных ранее понятий.

Обсуждение. С развитием теории функционального синтаксиса Пражской лингвистической школой акцент в изучении предложения сместился с его 
структурных характеристик на изучение актуального смысла. Появился новый термин - высказывание, под которым понимали информативную единицу, сформированную на основе структурной схемы предложения.

Было установлено, что в зависимости от коммуникативной установки 'говорящего' одно и то же предложение может передавать разную информацию. В высказывании была выделена тема - предмет сообщения, данное, и рема - элемент несущий основное содержание сообщения, новое.

«Основные элементы актуального членения предложения - это исходная точка или основа высказывания, то есть то, что является в данной ситуации известным или, по крайней мере, может быть легко понято из чего исходит 'говорящзий', и ядра высказывания, то есть то, что 'говорящзий' сообщает об исходной точке высказывания» - писал один из основоположников теории актуального членения предложения чешский ученый В. Матезиус [13, с. 239].

С появлением двух конкурирующих терминов для обозначения единицы коммуникации - предложения и высказывания - в лингвистике, в теории синтаксиса, в частности, возникла новая проблема, требующая решения, проблема разграничения предложения и высказывания. В рамках структурного синтаксиса она состояла в определении основы, структурной схемы построения высказывания, его сходства или несходства с предложением.

Так, например, в теоретической грамматике современного русского литературного языка выделяются две группы высказываний: высказывания, построенные по структурной схеме предложения и высказывания организованные по своим собственным схемам. Характерной особенностью первых является возможность функционирования в независимой позиции, вторых - функциональная зависимость от структуры текста. К функционально зависимым высказываниям относятся вторые реплики диалогических единств, части сложных предложений, контекстуально подготовленные компоненты сложного синтаксического целого, а также высказывания, понятность которых целиком определяется ситуацией речи [10, с. 575].

Так были выделены центральные структурные единицы - предложение (односоставное и двусоставное), и периферийные непредложенческие структуры, что и позволило сделать следующий вывод: всякое предложение есть высказывание, но не каждое высказывание является предложением [23, с. $23]$.

В большинстве современных семантических изысканий в области синтаксиса смысловая структура предложения моделируется либо с опорой на определение соотношения языка с миром реальности (ситуацией и её компонентами), либо с логикой развития мысли, (т.е. осознания и отражения языковыми средствами объективной действительности).

В логико-семантических исследованиях семантическая структура предложения состоит из элементов пропозиции (субъект, другие термы конкретного значения, предикат) и модуса, отражающего оценку и указание 
на коммуникативную цель, с которой применяется пропозиция. Основные типы предложений определяются на основе логико-синтаксических отношений связанных со способами мышления о мире: отношения экзистенции, идентификации, номинации и характеризации [1, с. 18-20].

В исследованиях аналогово синтаксиса $[18$, с. 13] основой семантической структуры предложения является предикатное выражение [4, c. 8], а в целом предложение рассматривается как иерархически организованная структура базисных и модификационных предикатов [23, с. 18], реляционного костяка (денотата) и компонентов модификационного уровня [20, с. 51$]$.

Общим как для логико-семантических теорий смысла предложения, так и для аналогово синтаксиса является выделение в структуре предложения двух семантических составляющих пропозиции / денотата / диктума / реляционного костяка / базисных предикатов и модуса / модификационных предикатов и т.д.

Под пропозицией в общем смысле понимается та часть смысловой структуры предложения, которая отражает отношения реальной действительности и представляет собой описание предмета или явления, либо реляционную структуру, описание отношения между предметами или явлениями объективной действительности в языковых формах.

Модус определятся как элементы смысла предложения связанные с объективной или субъективной основой представления пропозиции. К категориям модуса предложения обычно относят оценку соответствия предиката действительности в модальном и истинностном значении, отражение коммуникативных и информационных установок говорящего, условий и структуры речевого акта, эмоциональный аспект и т.д. [9, с. 19-26]

Что же касается смысловой структуры высказывания, то в большинстве исследований посвященных семантике предложения и высказывания структурно-семантические характеристики как предложения, так и высказывания едины, отличия носят функциональный и функциональносемантический характер.

Так, например, Н.Д. Арутюнова, выделяет в предложении номинацию и модус коммуникативной цели, определяя семантическую гетерогенность характерной особенностью предложения, а указание на коммуникативную цель с которой применяется предложение, характерной особенностью высказывания [1, с. 34-45], снимая, таким образом, противопоставление предложения и высказывания как двух разных единиц синтаксиса.

Несколько иную точку зрения высказывает Г.Г. Почепцов, считая, что высказывание является более крупной единицей, включающей предложение как составную часть: «высказывание, - пишет он, - понятие более широкое, полностью включающее в себя предложение и в дополнение к нему содержащее прогнозируемые характеристики общения / функционирования данного предложения» [16, с. 54]. 
Л.П. Чахоян разграничивает предложение и высказывание как структурно-семантическую и функционально-семантическую единицу, определяя различие между ними по форме номинации. «Предложение номинирует события, факты или явления объективной действительности, а высказывание дает номинацию речевого акта (эксплицитную, т.е. выраженную с помощью интонации или перформативных глаголов, или имплицитную, т.е. не выраженную прямо, а подразумеваемую) и номинацию фактов / событий объективной действительности» [23, с. 23].

В разграничении предложения и высказывания Л.П. Чахоян исходит из положения о пропозитивной сущности номинации предложения, противопоставляя ее модальной части или модусу. «Предложение передает номинацию не всем своим составом, а только той его частью, которая называется пропозицией» [23, с. 13].

Однако, представление смысловой структуры предложения как иерархически организованной семантической структуры, состоящей из базисных (предикатные выражения и номинация параметров ситуации), модификационных (включающие предикаты; предикаты-операторы, к их числу относятся кванторы, отрицание, модальные предикаты; модификаторы; импликаторы) и семантико-синтаксических элементов, по сути, говорит о знаковом выражении / наименовании, как элементов пропозиции, так и элементов модуса предложения. Это позволяет сделать вывод, что номинативную функцию предложения не стоит сводить к одной лишь денотативной стороне, семантическая структура предложения объединяет как денотативное, так и сигнификативное значение.

Аналогичная точка зрения представлена в исследованиях предложения и высказывания и форм их номинации Н.Д. Арутюновой, В.Г. Гака, Г.В. Колшанского [1, с. 37 ; 8 , с. $261 ; 11$, с. 125].

Инструментальные концепции языка занимаются изучением коммуникативного значения высказывания в его взаимодействии со строением предложения и коммуникативной ситуацией и рассматривают особенности его номинации. Основным свойством высказывания в данных концепциях является его направленность на достижение определенной цели [6, с. 47-54]. Следовательно, смысл высказывания как орудия, средства достижения цели определяется его употреблением. Так, опираясь на теорию речевых актов Дж. Остина и Дж. Сирля, Л.Д. Чахоян считает, что высказывание, например, «I gave her a book» помимо номинации события включает также имплицитную номинацию речевого акта, в данном случае сообщения. Его семантико-синтаксическая структура содержит перформатив I inform you.

В ситуативной концепции высказывания В.Г. Гака предложение и высказывание различаются не по форме номинации, она для них едина, номинативная сторона высказывания, равно как и номинативная сторона предложения включает в себя четыре аспекта: денотативный, модальный, 
социальный и информативный, а со стороны зависимости / независимости, т. e, степени связи последнего с ситуацией, что находит свое выражение в неполноте внешнего выражения, в его структурной схеме [8, с. 261].

В.Г. Гак выделяет следующие черты высказывания, определяющиеся соотношением структуры ситуации и структуры высказывания, зависимостью высказывания от ситуации, отношением говорящего к ситуации, общностью опыта собеседников: ситуативность, избирательность, компрессия и избыточность, модализация, информативность, уровневая интеграция и другие [7, с. 349-572].

Таким образом, высказывание определяется как функциональная единица равновеликая предложению, но отличающаяся от последнего тем, что ее анализ преследует цель не вскрыть ее общую абстрактную схему синтаксической организации, а показать, как она связана с ситуацией, какими средствами эта ситуация описывается.

В несколько ином аспекте рассматривает высказывание Н.А. Слюсарева. Ее подход можно назвать текстоцентрическим, так как во главу угла ставится выяснение соотношения высказывания и текста, способа включения высказывания в текст. Высказывание определяется как «наименьший и законченный в семантическом отношении отрезок текста, выделяемый интонационно в качестве отдельной единицы» [17, с. 67].

Что же касается соотношения предложения и высказывания, то его, в концепции Н.А. Слюсаревой можно определить следующим образом: направленность высказывания в две области - языка и речи - приводит к тому, что высказывание представляет собой единицу, которая является местом сосредоточия формально-структурного, т.е. собственно грамматического, и семантического (прерогатива предложения), и естественно функционального.

Итак, понятие предложения и высказывания соотносятся друг с другом с одной лишь разницей, высказывание в отличие от предложения имеет не только структурный, но и актуальный смысл, который передается одной и той же структурной единицей, предложением, по-разному, в зависимости от условий речевого контекста и ситуации.

Концепция высказывания И.Г. Торсуевой также строится на положении о том, что знание о явлении действительности предполагает знание о детерминантах его существования. Соотношение высказывания и текста в данном случае формулируются следующим образом - «знание о природе высказывания и его характеристиках является полным только тогда, когда определены детерминанты его существования в целом - в системе текста» [21, c. 65-66].

Следует отметить, что многоаспектность в изучении высказывания во многом предопределила существование различных аспектов описания единицы высшего порядка - текста, куда высказывание входит как составная часть. Так, например, трактовка высказывания как реализации выразительных возможностей, предоставляемых языковой системой всякий раз для 
конкретных задач и с определенным воздействием [14, с. 446] отразилась в рассмотрении феномена текста как реализации структуры языка.

Определение высказывания как событийной номинации, которая в качестве номината имеет микроситуацию, то есть, событие, факт, объединяющих ряд элементов, сыграло свою роль в рассмотрении текста как способа отражения объективной действительности.

В свою очередь определение текста как системы целостного в структурном и функциональном отношении образования, внутренняя связь элементов которого более необходима и устойчива, чем связь этих элементов с окружающей средой или элементами других систем, основными принципами организации которой является структурность, иерархичность, целостность взаимосвязь системы и среды, функциональность, объективность [21, с. 66] предопределили выделение в высказывании собственно текстовой части, элементов включающих его в более широкие коммуникативные рамки.

Рассмотрение текста как основной единицы коммуникации, особого вида деятельности; способа хранения и передачи информации, формы существования культуры, продукта определенной исторической эпохи; отражения психической жизни индивида и т. д. взаимосвязано с совмещением двух аспектов в изучении высказывания. С одной стороны собственно лингвистического, т.е. структурно-семантического, логического и коммуникативного аспектов, с другой стороны ситуативного, психо- и социолингвистического, мыслительно-познавательного, культурноисторического и прочих аспектов этого плана.

Итак, различия между предложением и высказыванием носят, как уже упоминалось выше, функционально-семантический (семантикосинтаксическая структура высказывания в отличие от предложения содержит перформативный глагол, указывающий на тип речевого акта) и функциональный характер.

В функциональных различиях предложения и высказывания можно выделить два аспекта. Аспект функциональной зависимости, т.е. формы устойчивой взаимосвязи предложения, как единицы системы языка, и высказывания, как единицы функционирования данной системы, и аспект внешнего проявления свойств высказывания, его функции в системе текста, что накладывает определенный отпечаток на форму и семантическую структуру.

Например, выделение в структуре высказывания элементов, которые указывают на связь пропозиции с референтной и коммуникативной ситуацией, собственно текстовых элементов, включающих его в рамки текста и т.д. Предложение и высказывание различаются как структурная и функциональная единицы. Их разграничение проводится только в направлении предложение $\rightarrow$ высказывание и опирается на функциональную трактовку взаимосвязи языка и речи, где речь определяется как сфера функционирования языка. 
Мы полагаем, что такой подход, безусловно, необходим и правомерен, так как позволяет определить некоторые характерные особенности структуры и особенности функционирования данных единиц. Он также дает возможность определить некоторые аспекты актуализации (соотнесения с действительностью и приспособления к требованиям данной речевой ситуации) потенциального знака - предложения и превращения его в актуальный знак - высказывание. Однако, в таком подходе опущена первая часть метода диалектического познания сущности явления восхождение от конкретного, чувственно-наглядного к абстрактному и представлена лишь вторая - восхождение познания от абстрактного к конкретному.

Возможно, такой подход является единственно верным при описании слова. Словесный знак, как основная когнитивная единица языковой системы, фиксирует, храня в скрытом виде, формы перехода фактов действительности в факты мышления, т.е. форму знания, отражая одновременно ступеньки и результаты познания. При переходе слова из знака виртуального в знак актуальный обобщенные виртуальные знаки, генетически производные от актуального проявления слова, становятся первоосновой, семантическим субстратом актуальных знаков [22, с. 82].

В диалектическом взаимодействии двух модификаций коммуникативной единицы - высказывания и предложения - вследствие того, что её смысловое содержание не поддается кодификации, оно всегда результат творческого мыслительного усилия, так как формируется в неповторяющихся ситуациях, главенствующую роль играет актуальный знак - высказывание, т.е. конкретное, единичное.

'Высказывание в речи', как чувственно-конкретное, является исходным пунктом познания 'высказывания как научного понятия' и его сущностных характеристик, воспроизведенных мышлением. Предложение как потенциальный знак, следовательно, абстрактное, является средней ступенью и средством познания конкретного - высказывания как научного понятия.

Выводы. В своем подходе мы опираемся на соотношение языка и речи как на «отношение между научным анализом, абстракцией, синтезом, классификацией, т.е. научной интерпретацией фактов, с одной стороны и определенными явлениями действительности, составляющими объект этого анализа, абстракции с другой» [12, с. 317].

Мы предлагаем рассмотреть незаконченное высказывание в рамках следующей функциональной модели: объективная реальность (объект отражения) $\rightarrow$ говорящий (отражающее устройство) / язык (средство отражения) $\rightarrow$ текст (результат отражения).

Подобная трактовка взаимоотношения языка и речи снимает, делает несущественной проблему соответствия или не соответствия высказывания структурной схеме предложения. Предложение как абстракция реальной структуры конкретного высказывания может иметь форму как двусоставного и односоставного предложения, так и любого другого структурного типа. В 
этом вопросе мы полностью согласны с утверждением В.В. Виноградова о том, что предложения в словесной ткани, которых не хватает одного или нескольких членов является своеобразными типизированными формами предложений разговорной речи, их особыми структурными типами, которые вовсе не представляют собой нарушения норм "полных" предложений, требуемых абстрактной грамматической схемой. Следовательно, изучать их необходимо не с точки зрения их предполагаемой недостаточности или неполноты, а со стороны их собственных специфических для них структурных свойств и функций [5, с, 29].

Объект отражения (объективная реальность) в данной модели не беспределен, исследуется лишь определенный его фрагмент, который нашел свое отражение в тексте. Текст рассматривается нами как «форма опосредованной номинации событий, поскольку в нем устанавливается соотношение не только между объектами, но и между ситуациями» [11, с, 132].

Центром и наиболее активным элементом данной модели является “говорящий”, выступающий в единстве его психологических и социальных характеристик, но не как “глобальная личность”, в которой слиты воедино все ее составляющие, а как личность “параметризированная”, выявляющая в акте речи одну из своих социальных функций или психологических аспектов, в связи с которыми и должно пониматься его высказывание [2, с. 357].

Вопрос о взаимодействии структуры высказывания, как единицы текста, и структуры ситуации решается нами в пользу «решающей роли онтологии, т.е. самой ситуации, ибо в любом другом случае разрушается принцип адекватности языкового выражения определенного мыслительного (понятийного) содержания (сигнификата - для языковых единиц), отражающего действительную ситуацию в её реальной денотативной структуре» [11, с. 127]. В конечном итоге, использование тех или иных языковых средств определяется замыслом однозначного и точного выражения понятийного содержания, относящегося к референту высказывания.

Необходимо отметить еще один аспект соотношения объективная реальность $\leftrightarrow$ говорящий $\leftrightarrow$ текст. Как отмечают представители психолингвистического направления в лингвистике, специфика речевой деятельности, как и любой человеческой деятельности вообще опредёляется целевой установкой. В процессе построения высказывания говорящий избирательно использует и комбинирует семантические и синтаксические блоки, таким образом выделяя те или иные актуальные для него аспекты ситуации.

Следовательно, высказывание осуществляет номинацию с определенной коммуникативной установкой. Кроме коммуникативной интенции, в речевой деятельности учитывается и вторая сторона коммуникативного процесса реакция собеседника на сообщение, При построении высказывания говорящий имеет целью не только отразить ситуацию в актуальном для него аспекте, но и сделать свою мысль понятной “слущающему”, т. е. учитывает фактор 
адресата. Адресат, как и говорящий, «вступает в коммуникацию не как глобальная личность, а в своем аспекте, амплуа или функции, соответствующем аспекту говорящего» [2, с. 357].

\section{ЛИТЕРАТУРА}

1. Арутюнова Н.Д. Предложение и его смысл. Москва: Наука, 1976. 378c.

2. Арутюнова Н.Д. Фактор адресата. Известия Академии Наук. Серия Литературы и Языка. 1981. №4, том 40. С.356-367.

3. Блох М.Я. Теоретические основы грамматики. Москва: Высшая школа, 1986. 383c.

4. Богданов В.В. О конструктивной единице смысла предложения. Предложение и текст в семантическом аспекте. Калинин: Изд-во КГУ,1978. С.6-17.

5. Виноградов В.В. Некоторые задачи изучения синтаксиса простого предложения. Вопросы языкознания. 1954. №1. С.3-29.

6. Витгенштейн Л. Логико-философский трактат. Москва: Изд-во Иностранная литература, 1958. 134c.

7. Гак В.Г. Высказывание и ситуация. Проблемы структурной лингвистики. Москва: Наука, 1973. С.349-0372.

8. Гак В.Г. К типологии лингвистических номинаций. Языковая номинация. Общие вопросы. Москва: Наука, 1977. С. 230-294.

9. Гак В.Г. О категориях модуса предложения. Предложение и текст в семантическом аспекте. Калинин: Изд-во КГУ, 1978. С.19-26.

10. Грамматика современного русского литературного языка (Под редакцией Н.Ю. Шведовой). Москва: Наука, 1970. 767c.

11. Колшанский Г.В. Лингво-гносеологические основы языковой номинации. Языковая номинащия. Общие вопросы. Москва: Наука, 1977. C.99-147.

12. Коржинек И.М. К вопросу о языке и речи. Пражский лингвистический кружок. Москва: Прогресс, 1967. С.317-337.

13. Матезиус В. О так называемом актуальном членении предложения. Пражский лингвистический кружок. Москва: Прогресс, 1967. С.239-245.

14. Матезиус В. Язык и стиль. Пражский лингвистический кружок. Москва: Прогресс, 1967. С. 446 -523.

15. Почепцов Г.Г. Конструктивный анализ структуры предложения. Киев: Выща школа, 1971. 179c.

16. Почепцов Г.Г. Высказывание и трансформация его свойств в неречевых формах общения. Структурная и математическая лингвистика. 1976.№4. C. 54-58.

17. Слюсарева Н.А. Проблемы функционального синтаксиса английского языка. Москва: Наука, 1981. 206с. 
18. Слюсарева Н.А. Проблемы функциональной морфологии современного английского языка. Москва: Наука, 1986. 215с.

19. Структурный синтаксис английского языка. Ленинград: Изд-во Ленинградского ун-та, 1972. 170с.

20. Сусов И.П. Семантическая структура предложения: на материале простого предложения в современном немецком языке. Тула, 1973. 141с.

21. Торсуева И.Г.Детерминированность высказывания параметрами текста Вопросы языкознания. 1986. №1. С.65-74.

22. Уфимцева А.А. Лексическое значение. Принцип семиологического описания лексики. Москва: Наука, 2002. 239с.

23. Чахоян Л.П. Синтаксис диалогической речи современного английского языка. Москва: Высшая школа, 1979. 166с.

УДК $811.111-342$

DOI: $10.24144 / 2617-3921.2020 .18 .143-157$

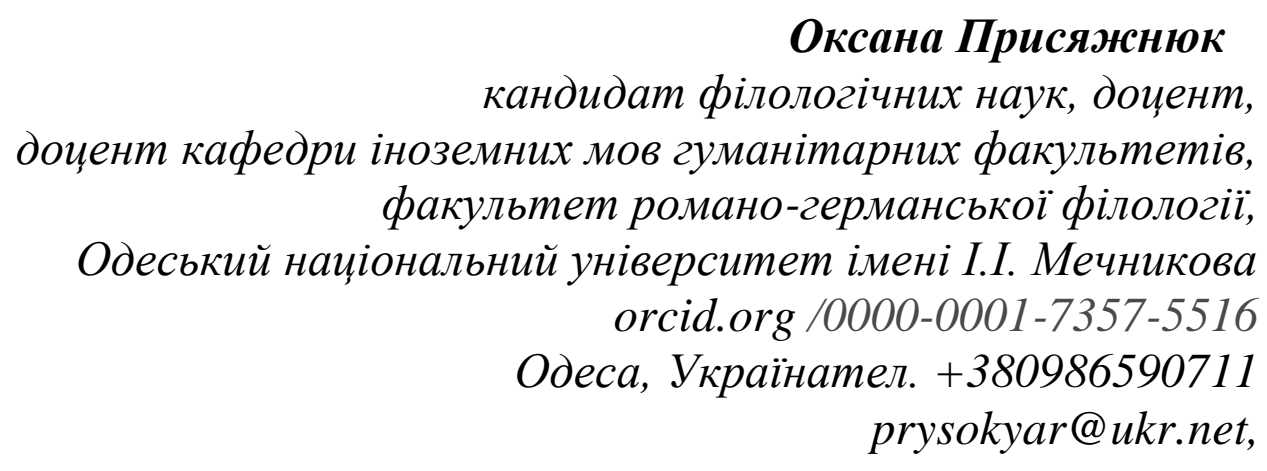

\section{Сприйняття північних діалектів україномовними білінгвами}

Анотачія. Стаття присвячена вивченню усної діалектно-забарвленої мови британського типу вимови в аспекті ї̈ сприйняття. Воно спрямоване на вивчення фонетичних характеристик, що відрізняють акценти північного регіону Англії від вимовної норми, а також на виявлення труднощів сприйняття, викликаних лінгвістичною невідповідністю діалектів літературної норми. Актуальність теми дослідження визначається тим, що для досягнення адекватного взаєморозуміння в зв'язку з варіативністю форм мови в різних діалектах національної мови виникає необхідність вирімення ряду проблем взаємодії лінгвістичних чинників літературної норми та регіональних діалектів в процесі мовної комунікації. Метою статті $\epsilon$ виявлення та аналіз характерних рис північних діалектів сучасної Англії, а також визначення глибини сприйняття усного дискурсу носіями орфоепічної 